\title{
Modeling and prediction of conduction delay in an unmyelinated axon
}

\author{
Yang Zhang ${ }^{*}$, Dirk Bucher ${ }^{2}$, Farzan Nadim ${ }^{1}$ \\ From Twenty First Annual Computational Neuroscience Meeting: CNS*2012 \\ Decatur, GA, USA. 21-26 July 2012
}

Conduction delay in axons is a function of the axon morphology, passive membrane properties and voltagegated ionic currents. Although conduction delay is usually assumed to be constant, indicating perfect temporal fidelity, recent work has shown that the delay of each action potential depends on the prior short- and long-term history of activity in the axon [1]. Violation of temporal fidelity leads to substantial variations in interspike intervals which has potential impact on temporal neural activity.

In experiments using the motor axon of the pyloric dilator (PD) neuron of the lobster, $H$. americanus, we measured conduction delay using Poisson random stimuli applied at different mean rates [2]. These measurements showed that the mean value and the variance of conduction delay increases as a function of stimulus time until these values reach a steady state at about 5 minutes post-stimulation. Even at steady state, conduction delay showed a non-monotonic relationship with stimulus frequency $\left(f_{\text {inst }}\right)$ : it was higher at small or large values of $\mathrm{f}_{\text {inst }}$ but has a minimum at $\mathrm{f}_{\text {inst }} \sim 45 \mathrm{~Hz}$. Moreover, bath application of dopamine drastically improved the temporal fidelity of conduction delay.

We have constructed a conductance-based model of the PD axon to examine the role of different ionic currents in shaping the history dependence of conduction delay. In addition to the standard Hodgkin-Huxley currents, this model includes a transient potassium current $\mathrm{I}_{\mathrm{A}}$ and a hyperpolarization activated inward current $\mathrm{I}_{\mathrm{h}}$, both of which have been characterized in this axon. The
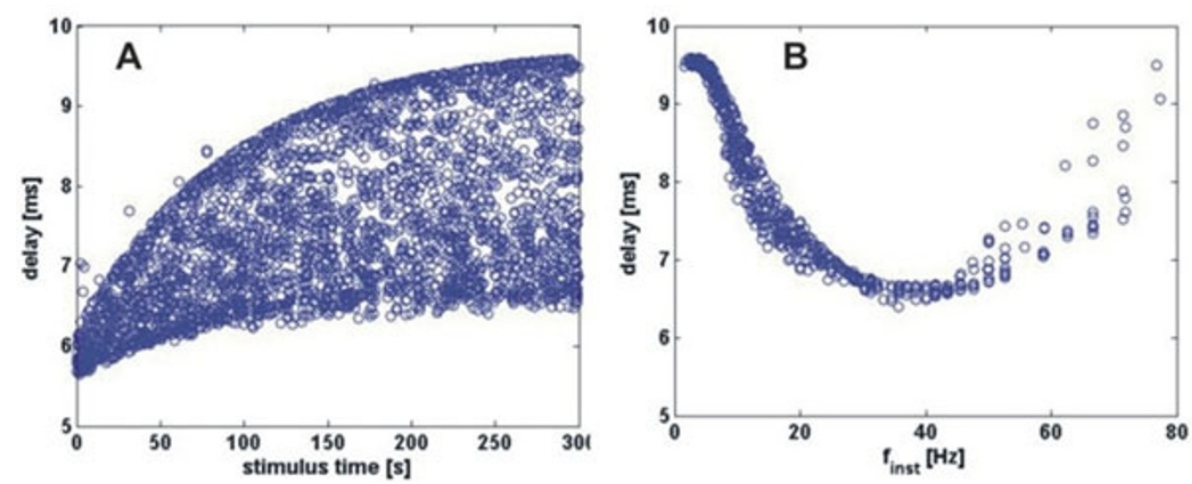

Figure 1 Changes in action potential delay in the model axon in response to 5 mins of Poisson stimulation (mean rate $10 \mathrm{~Hz}$ ). Compare with experimental data [2]. A. Both mean and CV of conduction delay increase slowly in response to activity. B. Delay (fifth minute) shows a nonmonotonic relationship with stimulus frequency.

\footnotetext{
* Correspondence: yz83@njit.edu

'Dept Math Sci and Dept Biol Sci, New Jersey Institute of Technology,

Newark, NJ, 07102, USA

Full list of author information is available at the end of the article
} 
main effect of dopamine in the biological axon is an increase of $\mathrm{I}_{h}$ which counteracts the activity-dependent hyperpolarization [3], mimicked by adding a $\mathrm{Na}^{+} / \mathrm{K}^{+}$ pump in the model.

We find that the $\mathrm{Na}^{+} / \mathrm{K}^{+}$pump enables the model to reproduce the long-term history dependence observed in the biological PD axon. A pump current with a slow time constant $(\tau=90 \mathrm{sec})$ results in a slow increase of the mean and $\mathrm{CV}$ of conduction delay with stimulus time (Fig. 1A), and a non-monotonic relationship between conduction delay and $\mathrm{f}_{\text {inst }}$ (Fig. 1B), as observed experimentally [2]. Additionally, as in the experiments, temporal fidelity is improved as $\mathrm{I}_{\mathrm{h}}$ is increased.

Action potential conduction velocity can be approximated by $v=\left(d /\left(8 R^{*} R_{a} C_{m}^{2}\right)\right)^{1 / 2}\left(d=\right.$ axon diam, $R^{\prime \prime}=$ total memb resistance/unit area at peak, $R_{a}=$ axial resistivity, $C_{m}=$ capacitance/unit area [4]. Although this equation accurately predicts the conduction velocity of a single action potential in our model, it fails to the variations in conduction velocity in the presence of the historydependent effects. This discrepancy is partly due to nonuniform conduction velocity along the axon when active at high rates. We revise the formula to predict the relationship between the conduction delay and total membrane resistance at the action potential peak.

\section{Acknowledgements}

Supported by NIH MH60605 and NS58825

\section{Author details}

'Dept Math Sci and Dept Biol Sci, New Jersey Institute of Technology, Newark, NJ, 07102, USA. ${ }^{2}$ The Whitney Lab for Marine Bioscience and Dept of Neuroscience, University of Florida, St. Augustine, FL, 32080, USA.

Published: 16 July 2012

\section{References}

1. Ballo AW, Bucher D: Complex intrinsic membrane properties and dopamine shape spiking activity in a motor axon. J Neurosci 2009, 29(16):5062-5074.

2. Ballo AW, Nadim F, Bucher D: Dopamine modulation of $I_{h}$ improves the temporal fidelity of spike propagation in an unmyelinated axon. J Neurosci 2012, 32(15):5106-5119.

3. Ballo AW, Keene JC, Troy PF, Goeritz ML, Nadim F, Bucher D: Dopamine modulates $I_{h}$ in a motor axon. J Neurosci 2010, 30:8425-8434.

4. Matsumoto G, Tasaki I: A study of conduction velocity in nonmyelinated nerve fibers. Biophys J 1977, 20:1-13.

doi:10.1186/1471-2202-13-S1-P81

Cite this article as: Zhang et al:: Modeling and prediction of conduction delay in an unmyelinated axon. BMC Neuroscience 2012 13(Suppl 1):P81.

\section{Submit your next manuscript to BioMed Central} and take full advantage of:

- Convenient online submission

- Thorough peer review

- No space constraints or color figure charges

- Immediate publication on acceptance

- Inclusion in PubMed, CAS, Scopus and Google Scholar

- Research which is freely available for redistribution

Submit your manuscript at www.biomedcentral.com/submit 